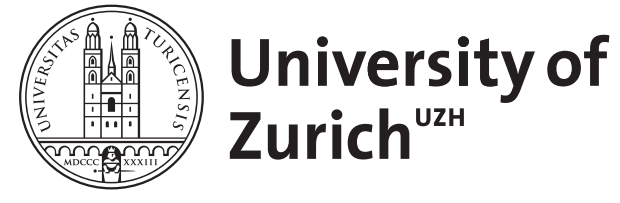

\title{
Concepts: where subjectivism goes wrong
}

\author{
Glock, Hans Johann
}

\begin{abstract}
The debate about concepts has always been shaped by a contrast between subjectivism, which treats them as phenomena in the mind or head of individuals, and objectivism, which insists that they exist independently of individual minds. The most prominent contemporary version of subjectivism is Fodor's RTM. The Fregean charge against subjectivism is that it cannot do justice to the fact that different individuals can share the same concepts. Proponents of RTM have accepted shareability as a 'non-negotiable constraint'. At the same time they insist that by distinguishing between sign-types and - tokens the Fregean objection cannot just be circumvented but revealed to be fallacious. My paper rehabilitates the Fregean argument against subjectivism. The RTM response rests either on an equivocation of 'concept'-between types which satisfy the non-negotiable constraint and tokens which are mental particulars in line with RTM doctrine - or on the untenable idea that one and the same entity can be both a shareable type and hence abstract and a concrete particular in the head. Furthermore, subjectivism cannot be rescued by adopting unorthodox metaphysical theories about the type/token and universal/particular contrasts. The final section argues that concepts are not representations or signs, but something represented by signs. Even if RTM is right to explain conceptual thinking by reference to the occurrence of mental representations, concepts themselves cannot be identical with such representations.
\end{abstract}

DOI: https://doi.org/10.1017/S0031819109000011

Posted at the Zurich Open Repository and Archive, University of Zurich

ZORA URL: https://doi.org/10.5167/uzh-18513

Journal Article

Published Version

Originally published at:

Glock, Hans Johann (2009). Concepts: where subjectivism goes wrong. Philosophy, 84(1):5-29.

DOI: https://doi.org/10.1017/S0031819109000011 


\title{
Concepts: Where Subjectivism Goes Wrong
}

\author{
HANS-JOHANN GLOCK
}

\begin{abstract}
The debate about concepts has always been shaped by a contrast between subjectivism, which treats them as phenomena in the mind or head of individuals, and objectivism, which insists that they exist independently of individual minds. The most prominent contemporary version of subjectivism is Fodor's RTM. The Fregean charge against subjectivism is that it cannot do justice to the fact that different individuals can share the same concepts. Proponents of RTM have accepted shareability as a 'non-negotiable constraint'. At the same time they insist that by distinguishing between sign-types and - tokens the Fregean objection cannot just be circumvented but revealed to be fallacious. My paper rehabilitates the Fregean argument against subjectivism. The RTM response rests either on an equivocation of 'concept' - between types which satisfy the non-negotiable constraint and tokens which are mental particulars in line with RTM doctrine-or on the untenable idea that one and the same entity can be both a shareable type and hence abstract and a concrete particular in the head. Furthermore, subjectivism cannot be rescued by adopting unorthodox metaphysical theories about the type/token and universal/particular contrasts. The final section argues that concepts are not representations or signs, but something represented by signs. Even if RTM is right to explain conceptual thinking by reference to the occurrence of mental representations, concepts themselves cannot be identical with such representations.
\end{abstract}

Concepts have occupied a central role in philosophy ever since the Socratic quest for definitions. But even if we abstract from merely terminological variations, concepts have been assigned a multitude of different and potentially conflicting roles. What we would nowadays call concepts have featured as:
- universals or properties
- components of propositions
- meaning(s) of linguistic expressions
- $\quad$ psychic or neurophysiological processes
- 'modes of presentation', ways in which we think of objects.

In spite of this diversity, one can detect a pervasive contrast between two fundamentally opposed approaches. ${ }^{1}$ According to objectivist or

1 A.J.P. Kenny, The Metaphysics of Mind (Oxford: Oxford University Press), 136; G. Rey, 'Concepts', in E. Craig (ed.), The Routledge 


\section{Hans-Johann Glock}

logical conceptions, concepts exist independently of individual human minds, e.g. as self-subsistent abstract entities or as abstractions from linguistic practices. According to subjectivist or psychological conceptions, concepts are mental phenomena, entities or goings-on in the mind or in the head of individuals.

The most prominent contemporary version of subjectivism is the representational theory of mind or 'RTM' championed by Fodor and his followers. Its central claim is that concepts are mental particulars. Fodor portrays his enemies as part of a wide-ranging conspiracy, which includes Ryle, Wittgenstein, neo-Fregeans, conceptual or inferential role semanticists, and holists of various sorts. He labels this conspiracy 'pragmatism', because it links concepts to inferential rules and abilities rather than to inner goings-on. And he has pronounced pragmatism to be 'the defining catastrophe of analytic philosophy of language and philosophy of mind in the second half of the twentieth century'. ${ }^{2}$

Many aspects of the Manichean struggle between RTM and pragmatism have been discussed in recent literature. ${ }^{3}$ My paper is devoted instead to a conflict which pits not just RTM against 'pragmatism', but subjectivism as such against any form of objectivism, including

Encyclopedia of Philosophy (London: Routledge, 1998) Vol. 2, 505; S. Laurence and E. Margolis, 'The Ontology of Concepts: Are Concepts Abstract Objects or Mental Representations?', Noûs 41 (2007), 561.

2 Quoted in T. Crane, 'Something Else, Surely', Times Literary Supplement (7.05.2004), 4. See: J. Fodor, Hume Variations (Oxford: Oxford University Press), 9 and 'Having Concepts: A Brief Refutation of the Twentieth Century', Mind and Language 19 (2004), 29-47. In this last article, he uses the less misleading label 'concept pragmatism' to cover all 'epistemic' accounts that treat concept possession as a kind of knowledge, including those which invoke knowing that rather than knowing how. But even in that article he does nothing to dispel the impression that RTM and pragmatism exclude one another. This is misleading, since one can be a representationalist while subscribing to conceptual role semantics.

See Volume 19.1 of Mind and Language (2004). Responding to Fodor, 'Having Concepts ...', op. cit. note 2, Weiskopf and Bechtel reject his allegation that pragmatism cannot avoid circularity in its account of concept possession, Prinz and Clark defend the pragmatist link between conceptual thought and action, Rey deplores his wholesale rejection of the 'Twentieth Century' on the grounds that it leads to a first-person meaning mysticism, and Peacocke insists that epistemic accounts of concepts are not committed to unacceptable consequences like making thought interpretation-dependent. Fodor gets the last word in 'Reply to Commentators', Mind and Language 19 (2004), 99-112. 


\section{Concepts: Where Subjectivism Goes Wrong}

Platonist accounts deriving from Frege. And it concerns not the issue of concept-possession, which has tended to occupy centre-stage in recent debates, but concepts themselves: Can RTM, as a version of subjectivism, account for the shareability of concepts?

For RTM, 'the mind is pre-eminently the locus of mental representation and mental causation' . ${ }^{4}$ It is a 'representational system', and thinking is 'representing things in the world'. ${ }^{5}$ So-called propositional attitudes like belief and desire are mental states, and they 'are constituted by relations to mental representations'. Furthermore, 'mental processes consist of causal interactions among these interrelated states and entities'; they are 'causal chains in which each link is sufficient for its successor'. 'The constituents of mental processes are causal interactions among ... ideas'. ${ }^{6}$

As regards concepts, the central thesis of RTM is that they are 'mental objects'. They constitute a kind of 'mental representation' and hence a 'kind of mental particular'. As mental particulars, they are 'objects in the mind' or 'in the head' of individuals; they are 'concrete' rather than abstract; and they have causes and effects in the physical world. ${ }^{7}$ As mental representations, they have 'representational content'. They occur as part of propositional attitudes, and what they represent contributes to the content of these attitudes, to what we believe, desire, etc. They do so by determining the conditions under which the attitudes in which they occur are true (in the case of beliefs) or satisfied (in the case of desires).

At present it is often assumed that the conflict between Fregean objectivists and representationalists simply rests on two diverse conceptions of concepts, serving different yet compatible interests. On the one hand, logicians, formal semanticists and conceptual analysts require a notion of concepts that makes them independent of individual people (whether it be as Fregean modes of presentation, sets of real or possible objects, functions on such entities, or as abstractions from intersubjective linguistic practices). On the other hand, psychologists, philosophers of mind and members of the artificial intelligentsia need a notion of concepts which captures the mental or neural processes of individual speakers or thinkers. ${ }^{8}$

Fodor, Hume Variations, op. cit. note 2, 8; see 7-10.

Crane, op. cit. note 2 .

Fodor, Hume Variations, op. cit. note 2, 8n, 141, 10.

Fodor, Concepts: Where Cognitive Science Went Wrong (Oxford: Oxford University Press), 3, 7-8, 22; Fodor, Hume Variations, op. cit. note 2, $13+\mathrm{n}$; Crane, op. cit. note 2 .

8 E.g, Rey, op. cit. note 1. 


\section{Hans-Johann Glock}

As we shall see, this conciliatory picture of the situation is too sanguine. ${ }^{9}$ On the one hand, any claim according to which concepts are phenomena in the minds of individuals faces an objectivist objection associated with Frege: concepts cannot be mental particulars since they can be shared between different individuals. On the other hand, some proponents of RTM, Fodor pre-eminent among them, not only regard their subjectivist approach as a superior research programme, but entirely dismiss the objectivist alternative. Thus Fodor lists the claim that concepts are mental particulars (i.e. mental causes and effects) as one of five 'not-negotiable conditions on a theory of concepts' ${ }^{10}$ Furthermore, like several other proponents of RTM he holds that the Fregean objection is fallacious, since it ignores the difference between type- and token-representations or -signs.

My first section introduces the Fregean argument and the RTM response. In the second section I show that this response misconstrues the Fregean argument, and that it ultimately rests either on an equivocation or on the untenable idea that one and the same entity can be both a shareable type and hence an abstract universal and a concrete mental particular. This absolves Frege of the charge of having committed a gross fallacy. But section 3 considers the further question of whether RTM might be protected from the Fregean argument by adopting unorthodox metaphysical theories about the contrasts between type and token and between universals and particulars. I deny this: the theories at issue are not just problematic in their own right, they also run counter to both the letter and the spirit of RTM. In the final section I argue that even by RTM's own lights concepts can be neither typenor token-signs, instead they must be something signified by signs. In other words, concepts are not symbolic representations but something represented by symbols.

\section{The Shareability of Concepts}

Frege uses the term 'idea' [Vorstellung] to signify what RTM calls a mental particular. Frege's ideas include sensations, but they also

9 On this point I agree with Sutton ('Are Concepts Mental Representations or Abstracta?', Philosophy and Phenomenological Research 68 (2004), 89-93) and Margolis/Laurence (op. cit. note 1, 589 n. 10. But whereas they opt for subjectivism (alias RTM or mentalism), I defend Frege's objectivist argument concerning shareability. Unlike Fodor, Laurence and Margolis, however, Sutton does not reject the Fregean argument as fallacious, and his position is compatible with it. See fn. 27.

10 Op. cit. note 7, 22. 


\section{Concepts: Where Subjectivism Goes Wrong}

include mental representations. Such an idea is capable of representing objects that are objective; yet the idea itself is subjective, i.e. 'something that belongs to the mental life of an individual' and is 'quite as private to the individual as his pleasure or pain'. Concepts, by contrast, are objective: they 'confront everyone in the same way'.11 Most importantly, concepts can be shared between different individuals, whereas ideas cannot.

One should never forget that the ideas of different people, however similar they may be-something which cannot, incidentally, be exactly determined-do not coincide but are to be distinguished. Each has his own ideas, which are not those of another. Here, of course, I understand 'idea' in the psychological sense. The vacillating use of this word causes confusion and helps the psychological logicians to conceal their failings. When will an end be put to this once and for all? Everything is eventually dragged into the realm of psychology; the boundary between the objective and the subjective disappears more and more, and even actual [wirkliche] objects are treated psychologically as ideas. ${ }^{12}$

For Frege ${ }^{13}$ a concept is the 'referent' (Bedeutung) rather than the 'sense' of a 'concept-word' or predicate; and it is 'senses' rather than concepts that are components of propositions (Gedanken). His most explicit statement on shareability contrasts ideas not with concepts themselves, but with these senses. There is an 'essential distinction' between the 'subjective' idea associated with a sign and its 'sense, which may be the common property of many people, and so is not a part or a mode of the individual mind'. Different people 'are not prevented from grasping the same sense, but they cannot have the same idea'. ${ }^{14}$

It is important to note that Frege's argument from the unshareability of ideas does not hinge on his tentative and highly problematic claim that the ideas of different individuals cannot be compared. ${ }^{15}$

11 G. Frege, Grundgesetze der Arithmetik, Vol. 1 (Jena: Phole, 1893), XVIII; see Grundlagen der Arithmetik; English translation The Foundations of Arithmetic (Oxford: Blackwell, 1953), X; 'Der Gedanke', in M. Beaney (ed.), The Frege Reader (Oxford: Blackwell, 1997), original pagination 66-7.

12 Frege, Grundgesetze..., op. cit. note 11, XVIII-XIX.

13 'Letter to Husserl 24.5.1891', in Beaney, op. cit. note 11, 149.

14 G. Frege, 'Über Sinn und Bedeutung', in Beaney, op. cit. note 11, original pagination $29-30$.

15 Cp. Laurence and Margolis, op. cit. note 1, 567. 


\section{Hans-Johann Glock}

Even if we can establish that $A$ and $B$ both have mental images of the Eiffel Tower, these images will still be situated in different minds and hence be numerically distinct. Fregean ideas are unshareable by definition: an idea in the mind of $A$ must be numerically distinct from one in the mind of $B$. But this does not settle the question of whether one can compare these ideas for their qualitative identity or difference, notably on the basis of how $A$ and $B$ describe their respective mental images.

What about the things that Frege regards as shareable? The sense of an expression is the 'mode of presentation' of its referent. Roughly speaking, the sense of a sentence is the thought expressed by it; the sense of a proper name is the features which determine what object, if any, is the referent of the name; the sense of a concept-word is the features which determine what objects, if any, fall under the concept-word.

Proponents of RTM often disregard Frege's distinction between senses or 'modes of presentations' on the one hand and concepts on the other. At least in the current context, however, this inaccuracy does not matter. Frege himself occasionally used 'concept' for the sense of concept-words. ${ }^{16}$ Contemporary neo-Fregeans like Peacocke and Künne adopt this line, and for good reasons. Our preconception of concepts distinguishes, for instance, not just the concept of a cordate from that of a renate, but also the concept of an equiangular triangle from that of an equilateral triangle. In other words, we individuate concepts not just more finely than Fregean referents (extensions) but also than properties or intensions, and just as finely as Fregean senses (which are shared by predicates only if the latter are synonymous). Most importantly, Frege's point about the shareability of senses extends directly to concepts; and this extension is very much part of his frequent insistence on the objectivity of concepts. According to Frege, the shareability of senses/concepts can be guaranteed only by treating them as abstract entities, entities which are what Frege calls 'non-actual' (by contrast to material objects) yet 'objective' (by contrast to mental phenomena like ideas).

Shareability ${ }^{17}$ is a feature of the ordinary concept of a concept in both everyday life and in disciplines like psychology and the history of ideas. One central use we make of 'concept' and terms

16 Posthumous Writings (Oxford: Blackwell), 253; 'Die Verneinung', in Beaney, op. cit. note 11, original pagination 151.

This term is preferable to Fodor's 'publicity': my nose is public in the sense of being accessible to more than one observer; but I am relieved to state that I do not share it with anyone. 


\section{Concepts: Where Subjectivism Goes Wrong}

that are equivalent in the relevant contexts (like 'conception', 'idea' or 'notion') is in claims about different individuals or even groups of individuals either sharing a concept, or failing to do so. For instance, different political and religious traditions may or may not share concepts like those of freedom of religion and of freedom of speech. Such claims are equally central to intellectual history, e.g. when it comes to comparing the Greek concept of eudaimonia with our concept of happiness.

Appeals to established use outside of cognitive science would normally be given short shrift by supporters of RTM. Yet even Fodor accepts as another one of his 'not-negotiable conditions on a theory of concepts' that 'concepts are public; they're the sorts of things that lots of people can, and do, share' ${ }^{18}$ At the same time, he thinks that he can easily account for shareability by introducing a distinction between type and token.

Peirce had introduced this well-known distinction for signs. ${ }^{19}$ In recent philosophy of mind it has been liberally extended beyond its semiotic roots to cover the difference between kinds of mental states and events on the one hand, and individual instances of these kinds on the other. For example, there is the 'type' believing that-dogs-bark and its so-called 'tokens', i.e. individual instances such as Anne's believing that-dogs-bark. In my view, this extension is problematic. ${ }^{20}$ Even if justified, however, such qualms need not affect Fodor's version of RTM. His 'language of thought hypothesis' treats mental representations as symbols and consequently invites the semiotic distinction that Peirce himself introduced. Fodor maintains that both the meaning of public languages and the intentionality of thought can be explained by a 'language of thought'. ${ }^{21}$ External sentences are meaningful because they are correlated with internal signs, sentence-like representations in the brain the tokening of which constitutes our thinking (believing, desiring, etc.). The ultimate carriers of intentional content are sentences in 'Mentalese',

18 Concepts, op. cit. note $7,28$.

19 C.S. Peirce, The Collected Papers of Charles Sanders Peirce, Vol. II (Cambridge, Mass.: MIT Press).

20 In both cases we have a repeatable entity and a non-repeatable entity. But the relation between believing that $p$ and Anne's believing that $p$ at time $t$ is that between a (universal) property and a particularised instance of that property (a trope), whereas the relation between a type-word and a particular occurrence of it appears to be closer to that between a universal property and the concrete object that instantiates it, which in our example would be Anne herself.

21 The Language of Thought (New York: Crowell). 


\section{Hans-Johann Glock}

physical tokens of computational types. When we engage in conceptual thought, Mother Nature inscribes words of a computer programme into our brains. Concepts, according to Fodor, are nothing other than the token-words of the language of thought:

... the mental particular that's in your head on occasions when you think $d o g$ is a token of the concept type DOG, just as the word that's on your lips when you say "dog" is a token of the word type "dog". In both cases, the tokens are concrete particulars and the types are abstracta. Likewise, the mental particular that's in your head when you think that (judge that) dogs bark is a token of the mental representation type DOGS BARK. ${ }^{22}$

This explains the shareability of concepts by distinguishing between type and token.

Since, according to RTM, concepts are symbols, they are presumed to satisfy a type/token relation; to say that two people share a concept (i.e. that they have literally the same concept), is thus to say that they have tokens of literally the same concept. ${ }^{23}$

Consider the scenario in which Anne and Sarah both believe that dogs bark and (improbably) utter 'Dogs bark' in close succession. In that case we are dealing with two tokens of a single type-sentence 'Dogs bark', and two tokens of a single type-word 'bark'. Similarly, according to Fodor, in Anne's brain there occurs one neural token-sentence, and in Sarah's brain there occurs another neural token-sentence. Yet Anne and Sarah both believe the same thing, namely that dogs bark, since both tokens instantiate the same Mentalese type-sentence DOGS BARK. Finally, they share the concept DOG, because both have tokens of one and the same Mentalese type-word.

\section{RTM vs. Frege}

This position can account for shareability. It does so at a price, however. The type/token distinction cannot be used to invalidate Frege's argument, since it implies abandoning the claim that concepts themselves are particulars. After all, what can be shared between different individuals are representation-types; and these types, as Fodor duly acknowledges, are 'abstracta' rather than mental particulars. To be more precise, types are repeatable universals

Hume Variations, op. cit. note 2, 13n; see Concepts. . op. cit. note 7, 3n. 


\section{Concepts: Where Subjectivism Goes Wrong}

and hence abstract. ${ }^{24}$ Conversely, what can qualify as mental particulars are representation-tokens; and these tokens are confined to each individual rather than shareable. This leaves RTM in a perilous position.

On the one hand, the non-negotiable constraint on a theory of concepts, namely that concepts be shareable,

is satisfied only by the abstract types

which are neither particulars (mental, physical or otherwise) nor concrete.

On the other hand, the central claim of RTM, namely that concepts are concrete particulars,

applies only to the tokens

which are not shareable.

At issue between RTM and objectivism is not whether concepts allow of a type/token distinction. ${ }^{25}$ It is whether concepts, the things which can be shared between different subjects, could be mental particulars, that is, tokens rather than types. As far as the Fregean objection is concerned, proponents of RTM are perfectly entitled to postulate a language of thought involving the tokening of sign-types. Still, if they persistently kept apart types and tokens, they would be forced to abandon the central claim of RTM, namely that concepts are mental particulars that can enter into causal relations. Instead they would have to acknowledge that concepts themselves are not particulars. This would still allow them to insist that conceptual thinking consists in the tokening of shareable types and hence in the occurrence of particulars. ${ }^{26}$ They would remain free to explain what goes

24 In a passage quoted below Fodor seems to adopt the orthodox distinction between particulars and universals. But in the last but one quotation and in his explanations of what it is for concepts to be mental particulars (quoted in my introduction) he contrasts particulars with abstracta, insisting that they are in the head and stand in causal relations. This inaccuracy does not matter for our purposes. For all universals are abstract (barring unorthodox views like that of Armstrong discussed in section 3). In any event, the contrast at the centre of the controversy between RTM and Frege is that between a particular confined to individual subjects and something shareable.

25 Pace Sutton, op. cit. note 9; Laurence and Margolis, op. cit. note 1, $567-9$.

26 Something akin to this fall-back position is adopted by Davis (Nondescriptive Meaning and Reference (Oxford: Oxford University Press, 2005)) and Sutton (op. cit. note 9, 92-4, 103). The latter explicitly concedes 


\section{Hans-Johann Glock}

on in the head of thinkers by reference to mental particulars. But they would not remain free to maintain that concepts, the things which by common consent must be shareable between different thinkers, are those mental particulars.

Unfortunately, many advocates of RTM resist any such concession. Rather than granting that the Fregean argument necessitates a substantial modification of RTM, from a doctrine about concepts to one about the tokening of concepts in thought, these inveterate subjectivists dismiss the argument. Thus Margolis and Laurence describe it as 'especially disappointing':

Frege is certainly right that each person has her own unique mental representation tokens, but the question is whether different tokens in different minds can be of the same type, and we see no reason why they can't be. The situation is, in principle, no different than it would be had Frege argued that two people can't literally utter the same sentence. While it's true that each will produce her own token, that doesn't mean that the utterances can't be instances of the same sentence type.... ${ }^{27}$

Margolis and Laurence accuse Frege of a 'type-token confusion'. ${ }^{28}$ This label is definitely misleading, since Frege never considered concepts in terms of a type/token distinction for mental representations,

the Fregean claim that subjects are related to abstract types, while insisting that they can do so only through the occurrence of concrete tokens. Contrast what Margolis and Laurence call 'the mixed view', a position they eventually reject as insufficiently subjectivist (op. cit. note 1, 569, 579-81). It is based on rejecting rather than accommodating the Fregean argument, and hence identifies concepts with mental particulars, while conceding that the latter are typed in terms of Fregean senses.

27 Laurence and Margolis, op. cit. note 1, 567; my emphasis.

28 They extend this charge to a Fregean argument by Peacocke ('Rationale and Maxims in the Study of Concepts', Noûs 39 (2005), 167-78) according to which the subjectivist equation of concepts with mental representations fails since there are concepts but not mental representations that will never be acquired by a subject. The response I give on Frege's behalf can be adapted to defend Peacocke: if concepts are to exist independently of subjects they must be types rather than tokens, and hence cannot be mental particulars. However, while all parties to the debate rightly assume that concepts can be shared, it is more controversial to maintain that concepts can exist even if they are never employed by a subject of conceptual thought. For what it is worth, I reject this claim while accepting an analogous claim about properties. 


\section{Concepts: Where Subjectivism Goes Wrong}

distinguishing instead between mental ideas and abstract senses. The real question is whether introducing the distinction permits subjectivists to insist, against Frege's objection, that concepts are mental representations and hence subjective particulars after all. The answer is No!

As Laurence and Margolis concede, tokens are unique to each individual. A token in $A$ 's head must be numerically distinct from a token in $B$ 's head. Consequently $A$ and $B$ cannot share the same token. But then, since concepts themselves are shareable, they cannot be identical with such tokens. By contrast to tokens, types of mental representations are shareable alright; and for this reason they are candidates for being concepts. Yet they are (abstract) universals rather than (concrete) particulars in the heads of individuals, which is just what objectivists have been claiming. Frege is not guilty of confusing type and token. Rather, Laurence and Margolis run together a claim that holds for the tokens postulated by RTM, namely that they are mental particulars, with a claim that holds for the types to which these tokens belong, namely that they are shareable.

Elsewhere, Laurence and Margolis write: 'mental representations are subjective in that their tokens are uniquely possessed; they belong to one and only one subject. Their being subjective in this sense, however, doesn't preclude their being shareable in the relevant sense, since, ..., two people can have the same representation by each having tokens of the same type' ${ }^{29}$ 'This does not furnish the riposte to Frege which they seek, however. For it concedes that concepts are not subjective in the straightforward sense in which he denied them to be, namely of being uniquely possessed by individuals. That tokens of concepts can be unique to individuals does not mean that concepts themselves can be. Worse still, the passage does not rehabilitate subjectivism. The 'mental representations' of which it speaks cannot be mental particulars, since they have to be abstract universals capable of being tokened in different subjects.

Unlike Laurence and Margolis, Fodor explicitly stresses that signtypes are abstracta. This concession willy-nilly carries over to concepts, since for him people 'have literally the same concept' in that they have 'tokens of literally the same concept'. ${ }^{30}$ Nevertheless Fodor tries to have his cake and eat it too. His argument is phrased mainly in terms of 'MOPs' or modes of presentation. But it is the

S. Laurence and E. Margolis, 'Concepts and Cognitive Science', in Concepts: Core Readings (Cambridge, Mass.: Bradford Books/MIT Press), 7.

30 Fodor, Concepts...op. cit. note 7, 28; my emphasis. 


\section{Hans-Johann Glock}

conclusions Frege draws from the publicity of concepts that Fodor is explicitly addressing here.

[Frege] thinks, quite wrongly that if MOPs are mental then concepts won't turn out to be public.... (perhaps this goes without saying), to claim that MOPs must be mental objects is quite compatible with also claiming that they are abstract objects, and that abstract objects are not mental. The apparent tension is reconciled by taking MOPS-qua-things-in-the-head to be the tokens of which MOPS-qua-abstract-objects are the types. It seems that Frege thought that if meanings can be shared it somehow follows that they can't also be particulars. But it beats me why he thought so. You might as well argue from 'being a vertebrate is a universal' to 'spines aren't things'. ${ }^{31}$

According to Fodor, Frege's argument fails because MOPs/concepts 'qua' mental particulars can be tokens, while 'qua' abstract objects they can be types. But this rebuttal suffers from precisely the kind of vacillation Frege diagnosed in his psychologistic opponents. The qua-operator that Fodor relies on is notoriously slippery. ${ }^{32}$ On one understanding it means in the capacity of, and ascribes two distinct roles to a single entity. For instance, qua environmentalist I welcome wind-farms whereas qua rambler I do not. On another understanding, 'qua' means in the sense of and functions as a tool of disambiguation. For instance, belief qua mental state or attitude -sometimes called a believing-differs from belief qua what is believed - the so-called (propositional) content.

31 Concepts...op. cit. note 7, 20-1. This passage disregards the fact that for Frege a concept is not the sense or mode of presentation expressed by a predicate. As mentioned above, this does not matter in the present context. The underlying question is whether whatever distinguishes co-extensional predicates and determines the contents of propositional attitudes is ipso facto in the head' as Fodor contends (1998: 15). Prima facie more threatening to my reading of Fodor's passage is the fact that it identifies a concept not with an MOP simpliciter, but with 'an MOP together with a content'. Nevertheless the passage directly concerns the shareability of concepts. Contents are ipso facto shareable by Fodor's lights; his task is therefore to show against Frege that MOPs are as well, in spite of being mental rather than abstract.

32 Frege already complained that psychologistic logicians exploit such fudge-operators in order to defuse the absurd consequences of their claims: "This "as such" is an excellent invention of authors who want to say neither yeah nor nay. But I do not brook such oscillation between the two, ...' (Grundgesetze der Arithmetik, op. cit. note 11, XXIII-XXIV). 


\section{Concepts: Where Subjectivism Goes Wrong}

Adopting this second understanding of 'qua', we must distinguish between two kinds of things signified by 'MOP' or 'concept'namely a mental particular on the one hand, an abstract entity on the other. This would mean, however, that Fodor's dismissal of the Fregean argument is based on equivocation. The Fregean claims that MOPs/concepts must be shareable and hence cannot be mental particulars; Fodor denies this by surreptitiously switching from one signification of 'MOP' or 'concept' - a type, which is an abstract universal-to another-a token, which is a concrete particular.

On the first understanding of 'qua', Fodor postulates a single entity which can fulfil different roles. Even in Fodor's own theory, however, there is no single entity which in one capacity is an abstract type and in another capacity a token, a mental particular that is non-abstract. Rather, there are two: the type which is abstract yet non-mental, and the token which instantiates the type and which is mental yet non-abstract. This is no coincidence, moreover, since no single entity could have the dual capacities that Fodor requires. If $x$ qua/in its capacity as (an) $S$ is $F$ and qua/in its capacity as $T$ is $G$, then it must be possible for $x$ to be both (an) $S$ and (a) $T$. Thus one and the same person can be both an environmentalist and a rambler. But nothing can be both abstract and a particular in Fodor's sense, since such a particular has a spatio-temporal location and stands in causal relations.

It might seem that I have been uncharitable to the inveterate subjectivists. Although they often express themselves in an awkward fashion, all they mean is this: there are token concepts, which are unshareable; but they are tokens of types of concepts that are shareable, just as different tokens of the Union Jack share one and the same design. This response would be adequate if the aim were to accommodate Frege's point by distinguishing between shareable concepts and their physical tokens. In fact, however, inveterate subjectivists reject Frege's argument as fallacious. Thus Fodor's uncharitable diagnosis of the Fregean argument runs as follows: the Fregean reasons from 'types are abstract' to 'tokens are not particulars', which is just as fallacious as reasoning from 'properties are universal' to 'instances of properties are not particulars'. But the Fregean is not guilty of any such howler. His argument simply relies on the difference between two kinds of entity: the type or property, which is abstract or universal, and the token or instance of the property, which is not. Acknowledging the difference between abstract types and their physical tokens is perfectly compatible both with the mandatory recognition that the two kinds of entity are connected and with 


\section{Hans-Johann Glock}

the plausible (though by no means truistic) claim that a type owes its existence to the existence of tokens that share a certain role or function (mutatis mutandis for universals and particulars).

The insistence that concepts are both shareable and particular faces an intolerable dilemma. Either it commits a fallacy of equivocation by reasoning roughly as follows:

$\mathrm{P}_{1} \quad$ Concepts (in the sense of types) are shareable.

$\mathrm{P}_{2} \quad$ Concepts (in the sense of tokens) are particulars.

$\mathrm{C}_{1} \quad$ Concepts are shareable particulars. ${ }^{33}$

$\mathrm{Or}$ it conjures up a chimerical amalgamation, some we-know-not-what which combines the useful property of being a universal and hence shareable or repeatable with the agreeable property of being a particular and hence in line with RTM doctrine.

\section{Metaphysical Escape Routes}

I do not see how the rebuttals of the Fregean argument that one finds in Fodor, Laurence and Margolis can be absolved from the charge of either committing an equivocation or invoking a category mongrel. But perhaps the Fregean argument can be blocked after all by modifying these rebuttals. There are various options here, and some of them raise issues that are hotly debated in contemporary metaphysics and which I cannot fully address in this context. Nevertheless I shall make out a case that these options are unviable because they are unattractive and incompatible with RTM.

33 Fodor cannot turn the tables on the Fregean by accusing her of the following equivocation: First Premise: Concepts (in the sense of types) are shareable; Second Premise: Mental particulars are not shareable; Conclusion: Concepts (in the sense of tokens) are not mental particulars. For neither the First Premise nor the Conclusion feature in her argument. The Fregean is not advancing any claims about concepts qua tokens or types. Rather, she accepts that concepts-the things with which we credit people in ascriptions of propositional attitudes and in intentional explanations-must be shareable-in line with Fodor's own professions. From this in conjunction with the Second Premise she validly infers that concepts (i.e. the aforementioned things which can be assumed to be shareable) are not particulars. At most one could reciprocate the charge of equivocation if the nonnegotiable constraint on concepts (the things with which we credit people, etc.) included that they are particulars. As mentioned above, this is what Fodor suggests in chapter 2 of Concepts...op. cit. note 7. But he does not use this constraint as a premise in criticizing objectivism; advisedly so, since such a line of reasoning would be blatantly question-begging. 


\section{Concepts: Where Subjectivism Goes Wrong}

Inveterate subjectivists could respond to the Fregean argument by avoiding the concession that the physical tokens of the language of thought are not shareable. At first sight this may seem attractive. The tokens of a public language can be shared, at least if they are inscriptions. For instance, two different demonstrators can hold up a single placard together.

The trouble is that this possibility does not extend to the tokens postulated by RTM, which are supposed to be phenomena in the mind or brain of an individual. What can be shared between different subjects of thought is not such a token but only a type-no matter whether a type is identified in typographic terms, as in public languages, or in the computational-syntactic terms that individuate the types of Fodor's postulated language of thought. With a bit of help from science-fiction one can conceive of a scenario in which two Siamese twins share neural firings. But this is out of the question for the standard cases in which, by common consent, concepts are shared nonetheless. When Anne and Sarah both think that dogs bark, what they have in common (granting the language of thought hypothesis) is the occurrence of tokens of the same type; they share the type DOG, and the property of having tokens of that type, but they do not share the tokens. Finally, returning to the analogy Fodor mistakenly invokes against Frege, what two spines share is the universal of being a vertebra, they do not share a specific instance of being a vertebra or being a specific instance of the property of being a vertebra.

But couldn't an inveterate subjectivist question the notion of shareability and sharing which I invoked against Fodor, Lawrence and Margolis? One might define shareability as follows: a representationtoken $x$ is shareable iff $x$ belongs to a representation-type which can be instantiated by many different tokens. On that understanding, the tokens themselves are the entities which can fulfil the dual requirements of being both particulars and shareable. But this gambit relies on an ignoratio elenchi. The Fregean pointed out that in the literal and straightforward sense concepts (representation-types) can and mental particulars (representation-tokens) cannot be shared, in that the former can and the latter cannot be possessed by two different individuals. This would suffice to show that concepts are not mental particulars, even if one could fashion a different notion of sharing which applies to both types and tokens. In fact, however, the notion of sharing and shareability now invoked by the inveterate subjectivist applies exclusively to the tokens. For the concept type is obviously not shareable in the sense of being a token of a type that can be variously instantiated. 


\section{Hans-Johann Glock}

That Sarah and Anne share a token in the artificial sense introduced by the inveterate subjectivist simply means that they have different tokens of the same type. Once more, what is the same between them concerns an abstract universal rather than a mental particular; therefore only the former, not the latter, is a candidate for being the concept which, ex hypothesis, they both possess. Consider the following analogy. It is perfectly legitimate to maintain that at this very moment two spatially remote individuals Anne and Sarah ride the same bicycle. But what one means is that their numerically distinct bicycles are of the same type. Glossing this fact by saying that they 'ride the same individual bicycle' and fending off inevitable protests by stipulating this to mean that their different bikes belong to the same type is at best a confusing verbal manoeuvre.

Neither equivocation, nor the idea of a type/token mongrel, nor the insistence that mental tokens can be shared is viable. One might accept this verdict, while trying to preserve the naturalistic-cum-physicalist aspirations that underlie RTM's resistance to the Fregean argument. Why not grant that shareable concepts would have to be types rather than tokens, while insisting that types no less than tokens can have spatio-temporal location and stand in causal relations? A precedent might be provided by Armstrong's suggestion that universals are 'wholly present' in each particular that instantiates them and hence located in space and time. ${ }^{34}$ If we apply this idea to our present topic, the following suggestion emerges: Rather than sharing a token, Anne and Sarah share a type which is nonetheless wholly located in their respective minds or brains.

There are strong arguments against the idea that a universal $U$ can be wholly present in two distinct and spatio-temporally separate particulars $x_{1}$ and $x_{2}$. In that case $U$ would have to be located where $x_{1}$ is and located where $x_{2}$ is. But since having the same spatio-temporal location is a transitive relation, this implies that $x_{1}$ and $x_{2}$ have the same spatio-temporal location. ${ }^{35}$ Furthermore, if the universal of being red were wholly present in a particular tomato, it could be destroyed by painting that tomato green. Unlike the previous consequence, this is not a contradiction; yet it is still absurd. ${ }^{36}$

34 D.M. Armstrong, Universals: An Opinionated Introduction (Boulder, Colorado: Westview Press, 1989).

35 E.J. Lowe, The Possibility of Metaphysics (Oxford: Clarendon Press, 1998), 156.

36 Even if sound, these remarks do not constitute a definitive refutation of Armstrong's theory of universals. For Armstrong himself wavers on the question of whether universals can really be located in space and time. 


\section{Concepts: Where Subjectivism Goes Wrong}

Both of these unpalatable consequences carry over directly to the suggestion that a type is wholly present in each of its tokens. Furthermore, invoking this variant of Armstrong's position is incompatible with the trajectory of RTM. Admittedly, it preserves the naturalistic assumption that concepts should be part of the causal order. But for RTM this assumption is intimately tied to the idea that concepts are mental particulars rather than universals that somehow manage to be concrete (and for good reasons, in light of the previous paragraph). Thus Fodor alleges that the failure to admit 'concrete particulars' in the mind is the original sin which prevents 'pragmatists' from doing justice to mental causation. ${ }^{37}$

We are now in a position to sharpen the Fregean objection to subjectivism. The constraint on concepts that RTM accepts fuels an argument the conclusion of which is the very opposite of what RTM claims:

$\mathrm{P}_{3} \quad$ Concepts must satisfy the non-negotiable constraints on concepts (the constraints that have to be respected by a theory of concepts), including that they be shareable.

$\mathrm{P}_{4} \quad$ Mental particulars cannot satisfy one of these constraints, since they are not shareable.

$\mathrm{C}_{2} \quad$ Concepts are not mental particulars.

Put differently, Fodor's contested 'constraint' that concepts be mental particulars is incompatible with the constraint which he shares with his objectivist opponents, namely that concepts be shareable. As we have seen, even the appeal to unorthodox metaphysical views does not provide grounds for condemning the Fregean argument as invalid. But the argument might still be unsound. Perhaps Fodor was precipitate in embracing shareability as a non-negotiable constraint. As we have seen, he accepts that different individuals like Anne and Sarah 'share a concept' in that they 'have literally the same concepts', which means that they have 'tokens of literally the

On occasion he suggests instead that they constitute space and time by being constituents of states of affairs, with space-time being the conjunction of all states of affairs (Universals...op. cit. note 36, 98-9). I shall not assess this proposal, since it does not lend succour to the idea that concepts might be types and nonetheless concrete occurrences in the heads of individuals. My aim was merely to show that the rejection of the Fregean argument cannot be based on a literal interpretation of Armstrong's text.

37 Hume Variations, op. cit. note 2, 136-142. 


\section{Hans-Johann Glock}

same concept'. This gives the game away, since it explicitly contrasts the concept itself with the particulars that are its tokens.

One might hold instead that Anne and Sarah can entertain the same thought not because they share a single concept DOG (which could not be a particular), but because they merely have distinct (particular) concepts which stand in a certain similarity relation, e.g. in that they play similar roles in their respective mental lives. Here one might take a leaf out of the book of metaphysicians who want to avoid universals by relying on particularized properties or 'tropes'. Rather than Anne and Sarah instantiating a universal which is strictly identical in the two cases-believing that dogs bark-Anne's and Sarah's respective believings that dogs bark merely stand in a certain similarity relation.

In the current debate about universals the crucial question at this juncture is whether this similarity relation presupposes a universal property after all. Fortunately, we do not have to decide this complex issue here. For as we shall see in the next section, Fodor himself explicitly rejects the suggestion that different individuals only have similar rather than numerically identical concepts, and on the basis of considerations that are central to RTM. ${ }^{38} \mathrm{He}$ thereby commits himself to the idea that concepts are objects that can be shared by different individuals, an idea which is incompatible with insisting that they are particulars unique to each individual.

38 Furthermore, even if the opponents of universals are right, their conception of particularized properties may be cold comfort for RTM. Consider first the reaction of a realist about universals to our particular example: if the two believings in the respective heads of Anne and Sarah resemble each other in their role or function (rather than their owner or their spatio-temporal location), then they must still have the same role or function, that is, fall under a universal. Their opponents resist the introduction of such a universal by insisting that similarity is a primitive concept. But even if similarity is primitive, i.e. a concept which cannot be further explained, it prima facie remains similarity in a certain respect. As a result opponents of universals like Heil (From an Ontological Point of View (Oxford: Clarendon Press, 2003), ch. 14) are driven to a further contention: while objects are similar or dissimilar in certain respects, this does not hold for (particularized) properties. Whatever the merits of this further move, however, it takes us beyond the board on which the debate of this paper is being played out. For the mental particulars of RTM are precisely objects rather than properties in Heil's sense. 


\section{Concepts: Where Subjectivism Goes Wrong}

\section{Representations or Things Represented?}

Even if Fodor owned up to the consequence that shareable concepts are not particulars, his position would still suffer from incoherence.

Very roughly, concepts are constituents of mental states. Thus, for example, believing that cats are animals is a paradigmatic mental state, and the concept ANIMAL is a constituent of the belief that cats are animals... mental states and processes are typically species of relations to mental representations, of which latter concepts are typically the parts. ${ }^{39}$

Nothing in Fodor's writings indicates that he distinguishes constituents from parts. In that case, however, it is difficult to see how he can avoid inconsistency. On the one hand, concepts are supposed to be constituents/parts of mental states and processes, which in turn are declared to be relations to mental representations. On the other hand, concepts are supposed to be constituents/parts of the mental representations themselves.

It is doubtful that there is any case of a thing being both part of a relation and part of one of the relata of that same relation. Superficial appearances notwithstanding, Fodor cannot restore consistency here by adopting a set-theoretic account of relations, even if, for the sake of argument, we assume the latter to be correct and to be compatible with his overall position. The set-theoretic account identifies a relation with a set of ordered $n$-tuples; but although the relata are elements of those n-tuples, the parts or components of the relation itself are the $n$-tuples rather than the relata. In any event, it is hard to make sense of the above quote in the context of RTM. For it commits Fodor to the untenable idea that when Anne believes that dogs bark the concept DOG is both a part of what she has in her belief-box-i.e. of the Mentalese token-sentence DOGS BARKand of the relation ' $\mathrm{x}$ has ... in x's belief-box'.

The former is Fodor's considered position: 'concepts are the constituents of thoughts' ${ }^{40}$, rather than of states or processes of thinking thoughts. But that position revolves around a more insidious oscillation between subjective and objective categories, in particular the realm of signs and the realm of what signs signify. Fodor continues:

I'll use 'thoughts' as my cover term for the mental representations which, according to RTM, express the propositions that

Concepts...op. cit. note 7, 6 .

Concepts... op. cit. note 7, 25. 


\section{Hans-Johann Glock}

are the objects of propositional attitudes. Thus, a belief that it will rain and a hope that it will rain share a thought, as well as a proposition which that thought expresses. For present purposes, it will do to think of thoughts as mental representations analogous to closed sentences, and concepts as mental representations analogous to the corresponding open ones. ${ }^{41}$

According to Fodor, Anne and Sarah do not stand directly in a relation of believing to the proposition that dogs bark. Rather, they stand in a relation to tokens of the thought or Mentalese typesentence DOGS BARK; and that thought expresses the proposition, it 'means that' Dogs bark. ${ }^{42}$ By the same lights, the concept DOG is a Mentalese type-word which has the property being human as its meaning.

At the same time, Fodor also suggests that 'word meanings just are concepts' ${ }^{43}$ Perhaps the tension is merely apparent, in that concepts are supposed to be both the meanings of the words of public languages and words of a mental language that mean properties. Yet Fodor nowhere indicates that this is what he has in mind. Worse still, one passage strongly suggests something more sinister. Fodor insists that we must recognize 'mental representations that express concepts', i.e. that concepts are meanings of mental rather than public symbols. ${ }^{44}$ Accordingly he is committed to the inconsistent idea that concepts are both mental words and the meanings of those very same words. ${ }^{45}$

This immediate inconsistency could be avoided by abandoning the second claim, according to which concepts are meanings. But a viable overall position emerges only by dropping the first claim and treating concepts as components of the contents of propositional attitudes, parts of what we think (believe, desire, etc.) rather than parts of representations that express or mean what we think. ${ }^{46}$ For it is central

\footnotetext{
41 Ibid.

42 See Fodor, Psychosemantics (Cambridge, Mass.: MIT Press, 1987), 17.

43 Concepts... op. cit. note 7, 2.

44 Hume Variations, op. cit. note 2, 13.

45 Consistency cannot be restored by pleading that the first claim refers
} to concept-tokens and the second to concept-types. For sign-types are not the contents or meanings of sign-tokens. The token 'dog', for instance, does not mean or express the sign type 'dog', it instantiates that type. What could mean the sign type are signs like "'dog"” or 'the word "dog”".

46 Like many contemporaries, Fodor equates meaning and content, e.g. when he describes believing that $p$ as standing in a computational relation to 


\section{Concepts: Where Subjectivism Goes Wrong}

to Fodor's case for the shareability of concepts that they should be components of the contents of propositional attitudes. His theory of concepts is supposed to explain the possibility of psychological explanations which are both intentional and 'nomic'; that is to say, they invoke general law-like connections between propositional attitudes. Such explanations require 'covering generalizations' about people who believe or intend that such-and-such, etc. As a result, RTM can underwrite psychological explanations of the required general kind only to the extent to which 'mental contents are supposed to be shared. If everybody else's concept WATER is different from mine, then it is literally true that only I have ever wanted a drink of water, and that the intentional generalization "Thirsty people seek water" applies only to me'. ${ }^{47}$

Intentional explanation presupposes 'a robust notion of content identity', which is tied to a robust notion of concept identity: belief contents and their component concepts are literally shared, rather than merely similar. This means that Fodor is absolutely right to accept shareability as a non-negotiable constraint. The only way RTM could resist the Fregean argument is by demonstrating it to be invalid, and that path has been blocked in the last section. It also means that Fodor is committed to the idea that concepts are components of propositional contents. For he insists that concepts are shared because people can literally believe the same. But what people believe is the propositional content of their beliefs.

It is not just that Fodor's specific argument for shareability requires that concepts be parts of what we think rather than of representations, of mental sentences which express what we think.

a mental representation that 'means that' $p$. In my view, this equation is untenable. A proposition, propositional content or thought is something that is or could be said or believed - a sayable or thinkable. It is something expressed or conveyed by the use of a sentence, not the meaning of a sentence. Unlike the meaning of a sentence, what is said (believed, etc.) can be true or false, implausible or exaggerated (R. Cartwright, 'Propositions', in his Philosophical Essays (Cambridge, Mass.: MIT Press, 1987), 33-53; A. White, Truth (London: Macmillan, 1970), 14; W. Künne, Conceptions of Truth (Oxford: Oxford University Press, 2003), 368-72). Furthermore, far from being identical with sentence-meanings, what is said on a particular occasion depends on sentence-meaning and context of utterance. In the present context, however, the difference can be ignored. The important point is that concepts are situated not at the level of signs but at the level of what signs mean or have as content when they are used.

47 Concepts...op. cit. note 7, 29; see 7. 


\section{Hans-Johann Glock}

The alternative assumption simply cannot account for shareability. Peacocke points out that 'It is possible for one and the same concept to receive different mental representations in different individuals' ${ }^{48}$ And according to Rey, even mental representation types need no more be shared between individuals that entertain the same thought than the type words need to be shared in sentences of public languages that express the same proposition.

One person might express the concept [city] by the word 'city', another by the world 'ville'; still another by a mental image of bustling boulevards; but, for all that, they might have the same concept [city]; one could believe and another doubt that cities are healthy places to live. ${ }^{49}$

Laurence and Margolis try to rebut this argument on two grounds. First, they deny that different types of mental representations can express the same concept, since they 'will have substantially different inferential roles'. Secondly, even if different types of internal representations could express the same concept this would raise 'no difficulties for the view that concepts are mental representations':

If two or more different representations of different types express the same concept, then, of course, that concept cannot be identified with one or the other of these two types. But there is no reason why the concept shouldn't be identified with a broader more encompassing type-one that has the mental representations of these other two types among its tokens. Just as particular Persian cats can be cats alongside Siamese cats and tabbies, so tokens of different types of representation can all be instances of a broader representation type. ${ }^{50}$

This response betokens a misunderstanding of the type/token distinction. Persian and Siamese cats both instantiate the kind cat or the property of being a cat. But there is no symbol or representation type of which both 'city' and 'ville' are tokens. Of course, they have something in common. Yet it has nothing to do with either the typographic level at which type-words in public languages are individuated or the syntactic computational level at which type-words in Mentalese are supposed to be individuated. It lies rather at the

48 A Study of Concepts (Cambridge, Mass.: MIT Press, 1992), 3.

49 'Concepts', in S. Guttenplan (ed.), A Companion to the Philosophy of Mind (Oxford: Blackwell, 1994), 186; see also. S. Schiffer, 'Lessons in Mentalese', Times Literary Supplement (26.06. 1998), 15.

50 'Concepts and Cognitive Science', op. cit. note 30, 76. 


\section{Concepts: Where Subjectivism Goes Wrong}

semantic level: both mean the same, they represent the same kind of thing. ${ }^{51}$

One might protest that neither Rey's passage nor the response by Laurence and Margolis really engage with RTM, at least in the version Fodor advocates. According to the language of thought hypothesis, anyone who thinks that cities are crowded must ipso facto have a Mentalese sentence of the type CITIES ARE CROWDED in her belief-box, irrespective of what images or words from natural languages may cross her mind.

Far from defusing the more general objection, however, this protest merely suggests that the language of thought hypothesis with its type/token distinction taken from semiotics is inapposite in the case of thought. Even if computationally individuated patterns of neural firing can be symbolic representations ${ }^{52}$ they will not have to be shared by people entertaining the same thought. Fodor's representation types are individuated not typographically, but through their syntax, through how they are cognitively processed. Yet $A$ and $B$ may have one and the same belief, and this belief may involve one and the same concept, without there being anything that is processed in the same way in both. If you associate the term 'grandmother' with an image of your grandmother and I associate it with the first line of Brahms' Lullaby, this is no bar to our expressing the same concept by it. Similarly, if, for the sake of exemplification, we accept the popular idea that neural networks present cities pictorially and digital computers present them symbolically, it is clear that the representations cannot be processed in the same way; yet this is no bar to them expressing the same concept. Note, finally, that believing cities are crowded can lead to different conclusions and actions in $A$ and $B$. $A$ may conclude that cities are desirable places and seek to live in them, while $B$ may draw the opposite conclusions. There is no reason why one and the same concept should not play slightly different roles in the thinking of different individuals.

51 To be sure, in aesthetics we encounter an extension of the semiotic distinction which might accommodate Laurence and Margolis. It treats a literary work such as Anna Karenina as a type, of which, e.g. Solzhenitsyn, Bloom and I possess different tokens, notwithstanding the fact that these tokens are spelled differently. But this terminological extension of the notion of a type in no way alters the crucial fact: what is common to the envisaged representations of cities lies at the semantic rather than the typographic or syntactic level.

52 Contrary to H-J. Glock, 'Neural Representationalism', Facta Philosophica 5 (2003), 105-29. 


\section{Hans-Johann Glock}

Laurence and Margolis are right to insist that one and the same concept cannot play different inferential roles in the cognition of different individuals. But, their second response to Rey notwithstanding, this kind of equivalence is ensured in the case of 'city' and 'ville'. That $x$ is densely populated, for instance, follows equally from the fact that $x$ satisfies 'city' and that $x$ satisfies 'ville'. The problem for RTM is that the roles that need to be shared between representations to ensure sameness of concepts are, trivially, those which are constitutive of conceptual content. This not only contradicts Fodor's adamant rejection of any kind of analytic/synthetic distinction, it also makes the sharing of concepts once more dependent on the semantic level of meaning or content.

On a coherent account that preserves the connection between concepts and shared thoughts (in the sense of thinking the same content), a concept is neither a token-nor a type- sign. Rather, it is what is signified or expressed by such signs. It is central to RTM that 'concepts are symbols'. ${ }^{53}$ Yet concepts cannot themselves be symbols (whether mental or public), since they are among the kinds of things which symbols represent. ${ }^{54}$ In a Teutonic vein, you might speak of 'Frege's Revenge'. ${ }^{55}$ In an American vein, you might exclaim: 'Any way you cut up the pie, concepts ain't in the head!'.

53 Concepts...op. cit. note 7, 28.

54 I deliberately leave open the precise nature of this semantic relation of representing. My preference is to adopt Künne's (Conceptions of Truth, op. cit. note 48, ch. 1) distinction between application, signification and expression: The concept-word 'dog' applies to dogs, signifies the property of being a dog, and expresses the concept of being a dog. Of course there are alternatives to this terminology, and there may be superior accounts of concept-words. But this does not affect my point against RTM, namely that concepts are not themselves symbolic representations, but something which stands in a semantic relation to such representations.

55 At the same time, the Fregean position preserves a connection between concepts and representation. Concepts are neither symbols nor subjective representations of a different (e.g. iconic) kind, but they are 'modes of presentation', i.e. ways in which different subjects can think of something. This opens up the possibility of treating concepts both as things represented-namely things expressed by concept-words-and as representations-namely ways of presenting properties (see W. Künne, 'Properties in Abundance', in P. F. Strawson and A. Chakrabarti (eds.), Universals, Concepts and Qualities (Aldershot: Ashgate, 2006), 263-6. My criticism of RTM does not rule out this option. Alas, it is difficult to spell out, especially if one seeks to avoid both the Scylla of subjectivism and the Charybdis of Platonist myths about a 'third realm'. 
A version of RTM which takes these lessons on board will still be a representationalist model of the mind in general and of conceptual thinking in particular. Yet it will no longer constitute a genuinely subjectivist position about concepts. RTM's case against objectivism has evaporated, and its case against concept pragmatism has to be re-jigged as follows: we entertain conceptual thoughts not by exercising an ability, but through the occurrence of neural tokenings of symbolic types; and we share a conceptual thought if those types have the same meaning or content. This case ought to be resisted, in my view. In that context one should also try to provide an account of the shareability of concepts which avoids both subjectivism and the Platonism of Frege's own brand of objectivism. The purpose of this paper was more modest, namely to rehabilitate the Fregean argument against the idea that concepts are mental particulars. ${ }^{56}$

University of Zürich

56 For comments I should like to thank Peter Hacker, John Hyman, Wolfgang Künne, Christian Nimtz, Oliver Petersen and Mark Textor, as well as audiences at Reading, Edinburgh, Leeds, Berlin, Bern, Geneva, Essen and Konstanz. I am particularly grateful to Javier Kalhat for suggestions and editorial help. 